Brit. J. vener. Dis. (1957), 33, 13.

\title{
CONGENITAL SYPHILIS IN ONE OF TWINS*
}

\author{
BY \\ SYDNEY M. LAIRD \\ Director, St. Luke's Clinic, and V.D. Department, Royal Infirmary, Manchester
}

When congenital syphilis occurs in twins the degree of clinical involvement can vary greatly between one twin and the other (Haslund, 1924; Dennie, 1924) and caution is therefore required in claiming that one of twins has escaped, infection. Several examples have been reported but those before 1906, being based on clinical and autopsy findings only, should probably be discounted. Later examples in infants, based on serological and radiological studies, are more acceptable, but here again inadequate length of follow-up, "carry-over" of maternal reagin to one infant, and non-specific radiological changes may have contributed to fallacious conclusions.

In the investigation of grown-up twins for serological evidence of previous syphilis, relative insensitivity of the standard serological tests (STS) in the early decades after 1906 may have introduced errors of interpretation, and one might now demand not only negative STS but also a negative treponemal immobilization test (TPI) before concluding that one of grown-up twins has escaped infection. Non-venereal, acquired syphilis in infancy or early childhood (Murrell and Gray, 1947; Eisenberg, Plotke, and Baker, 1949; and Rees, 1954) in one twin only must also be considered.

Haslund (1924) surveyed the early literature and collected reports on about twenty cases. He considered that none of them satisfied his criteria which were:

(1) Adequate knowledge of the previous history of both parents.

(2) Clinical and serological examination of both parents.

(3) Clinical and serological examination of both twins with autopsy in the event of death.

(4) Observation of the healthy child for at least 6 months.

(5) Detailed examination of the placenta.

\footnotetext{
* Received for publication November 28, 1956.
}

The case reported by Haslund satisfied all these criteria except for (5). Buhe (1889), quoted by Haslund, recorded autopsies on binovular twins of which one, who was stillborn, was infected and the other, who died on the 8th day, presented no signs of syphilis. Dennie (1924) reported one set of twins (No. 4) aged 5 years in which syphilis could be diagnosed in one twin only. Smith and Spence (1941) reported two examples seen personally at Johns Hopkins Hospital, two other examples from the hospital records, and one example seen privately by Earle Moore. These four examples at Johns Hopkins Hospital were noted among $\mathbf{4 4}$ twin pregnancies in forty women with syphilis, suggesting that the occurrence is not too rare. In reviewing the literature up to 1940, Smith and Spence found five examples which were completely acceptable, and two suggestive examples in which, however, observation was too short; in five further examples the children were first examined at an age at which spontaneous cure or acquired infection in early childhood could not be excluded. Smith and Spence laid down the following criteria which should be satisfied before accepting that congenital syphilis was present in one and absent in the other twin:

(1) The history and clinical and serological examination of the parents and any siblings must make congenital syphilis probable.

(2) Examination of the placenta and foetal membranes and of the uninfected twin itself, including the cerebro-spinal fluid and radiographs of the long bones, must be negative and observation must extend over at least 6 months.

(2) The congenital nature of the syphilis in the infected twin must be proved beyond doubt.

(4) It must be certain that the apparently uninfected infant is not latently developing the disease or, when seen for the first time at a later age, that the twin has not had syphilis.

(5) Repeated physical and serological examinations must be made in both twins, with autopsy in the 
case of death. James (1951) reported an example of an infant which satisfied these criteria except that the period of observation of the uninfected twin was too short. Wile and Welton (1938) suggest largely similar criteria and report one convincing example in male twins who were aged 18 years at the time of investigation.

\section{Case Reports}

Case 1, an unmarried mother, aged 27 years, was delivered of twins in hospital on September 9, 1945. Separate placental and amniotic sacs were reported, and it was noted that the first twin was born before rupture of the second amniotic sac. It was known that her Wassermann Reaction (WR) and Kahn test were negative $4 \mathrm{mths}$ previously. The puerperium was normal, and mother and twins were well on discharge from hospital. The mother and twins were first seen by me in the V.D. Clinic on January 3, 1946. The female twin had florid infantile syphilis including snuffles, specific eruption around the mouth and buttocks, enlarged liver and prominent abdomen, and a wizened appearance caused by dehydration and wasting. The WR and Kahn test were strongly positive. This female twin was admitted to hospital and made a good recovery after treatment with penicillin (1 mega unit). Her STS were negative on June 13, 1946, and September 11, 1947.

On January 3, 1946, the male twin was noted to be bigger, heavier, and free from clinical evidence of congenital syphilis. His WR and Kahn test were negative, and at subsequent examinations over $18 \mathrm{mths}$ the clinical and serological findings were negative.

On January 3, 1946, the mother did not show any clinical evidence of syphilis but the results of the STS were strongly positive, and she was treated with arsphenamine and bismuth preparations as an out-patient. After two courses of ten injections of each drug, the STS had become negative by August 8,1946 . This early seroreversal was expected and was in keeping with the diagnosis of early latent acquired syphilis in the mother. She was known to be promiscuous, she did not know the father of her twins, and had clearly acquired syphilis during the latter half of pregnancy. The mother defaulted after September, 1947, but was seen with the twins casually outside hospital in December, 1952. The female twin had Hutchinsonian incisor teeth and frontal bossing, but in terms of growth and general development was the equal of her uninfected twin brother.

Case 2, an unmarried male labourer aged 25 years, was seen on July 19, 1956. He had volunteered as a blood donor and his WR and Kahn test were found to be strongly positive. $\mathrm{He}$ was of short stature and clinical examination revealed bilateral optic atrophy with large circular pupils which failed to react to light. Visual acuity was $6 / 36$ for both eyes. No other abnormality was found in the central nervous system, and the cardiovascular system seemed normal. Stigmata of congenital syphilis included frontal bossing, anterior thickening of tibiae, antero-posterior thickening of the upper central incisor teeth, and some scarring of the left cornea from previous interstitial keratitis.

The patient's father had died aged 67 years from carcinoma of the stomach. His mother was alive and well, and was known to have had four pregnancies, as follows:

(1) Female, alive and well.

(2) Twin sons, including the patient, aged 25 years.

(3) Son, aged 24 years.

(4) Daughter, born in 1935, who died in infancy.

The twin brother showed no stigmata of congenital syphilis, and the WR, and Kahn and TPI tests were negative. He was not identical with his twin and in addition he was taller and better developed.

\section{Discussion}

Congenital syphilis should normally involve both twins but, although a proportion of the recorded exceptions are open to question, some reports and the two cases described above leave no doubt that congenital syphilis can occur in only one of twins. Infection of the products of conception via sperm or ovum is no longer an acceptable hypothesis and placental infection is the widely agreed mechanism. Where only one of binovular twins is infected it can be postulated that spirochaetes have crossed one placenta and not the other. To explain unequal involvement in monovular identical twins one must assume that spirochaetes have penetrated through only a part of the placenta. While such a happening may be possible it seems most unlikely, and none of the recorded cases in uniovular twins is completely convincing. The biometric and other features for establishing the identity of twins are considered by Penrose (1937) and Wile and Welton (1932), and the latter authors also draw attention to the difficulties and fallacies of decisions based on examination of the foetal membranes and placental relations. It seems probable that chance is the main and perhaps only factor in determining foetal infection, the greater the degree or frequency of maternal spirochaetaemia the greater the chance of foetal infection and the less the possibility of one of twins escaping infection.

The first of my two examples is unequivocal: acquired infection of the affected twin is most unlikely as the mother's infection was latent and clinical and serological observation of the other twin was prolonged enough to exclude infection. As the latter twin remained healthy and serologically negative, no radiological examination was undertaken. In the second example, the presence of stigmata and, in particular, the evidence of past interstitial keratitis, confirms that his infection was congenital and not acquired; the negative TPI is good evidence that his 
twin had never been infected and supports fully the negative clinical findings. In both examples, no treatment was given to the uninfected twin and this is an important decision of policy. In the example described by James (1951), the very full investigations are vitiated by the fact that the "uninfected" twin was treated at the age of 3 weeks when all findings were negative. With more prolonged observation and the withholding of treatment, this twin might well have proved to be infected.

\section{Summary}

The placental passage of syphilis from mother to foetus probably depends on chance, and infection of only one of twins seems a reasonable, if uncommon, happening. The possibility is more likely to occur in binovular twins and the reported examples in monovular twins are all open to question. The criteria for establishing this phenomenon are discussed and two examples in binovular twins are reported.

\section{REFERENCES}

Buhe, E. (1889). Quoted by Haslund, (1924).

Dennie, C. C. (1924). Med. Clin. N. Amer., 7, 1219.

Eisenberg, H., Plotke, F., and Baker, A. H. (1949). J. vener. Dis. Inform., 30, 7.

Haslund, O. (1924). Ann. Derm. Syph. (Paris), 6 ser., 5, 321.

James, T. (1951). Brit. J. Derm., 63, 389.

Murrell, M., and Gray, M. S. (1947). Brit. med. J., 2, 206.

Penrose, L. S. (1937). Lancet, 1, 322.

Rees, E. (1954). British Journal of Venereal Diseases, 30, 19.

Smith, F. R. Jr., and Spence, J. M. Jr. (1941). Sth. med. J. (Bgham,

Wile, Ula. J., 34, 147. Welton, D. G. (1938). Amer. J. Syph., 22, 544. 